DOI: 10.12731/2227-930X-2020-2-29-37

УДК 004.94

\title{
АЛГОРИТМИЗАЦИЯ УПРАВЛЕНИЯ НЕКОТОРЫМИ РЕСУРСАМИ В СИСТЕМЕ ПЕРЕВОЗОК
}

Львович Я.Е., Преображенский А.П., Чопоров О.Н.

В статье рассматривается задача, связанная с созданием оптимизационной модели для интеллектуального управления ресурсами в системе перевозок. Приведена структура системь, позволяющей осуществлять рейтинговое управление. Предлагается применение игрового подхода для алгоритма интеллектуальной поддержки.

Ключевые слова: система перевозок; оптимизация; ресурс; рейтинг.

\section{ALGORITHMIZATION OF MANAGEMENT OF SOME RESOURCES IN THE TRANSPORTATION SYSTEM}

\section{Lvovich Ya.E., Preobrazhenskiy A.P., Choporov O.N.}

The paper considers the problem associated with the creation of an optimization model for the intelligent management of resources in the transportation system. The structure of the system allowing rating management is given. The application of the game approach for the intellectual support algorithm is proposed.

Ключевые слова: transportation system; optimization; resource; rating.

\section{Введение}

В настоящее время можно наблюдать процессы развития цифровизации в различных сферах. Это относится и к организациям, связанным с перевозками. Представляет интерес осуществлять 
процессы их управления на базе разных подходов, связанных с рейтинговыми оценками, иллюстрирующими эффективность того, как они работают [1].

\section{О постановке задачи}

Предположим, что система, связанная с перевозками управляется в определенный временной период $t \in\left[T_{1}, T_{k}\right]$, где $k=1 . . K$. Но также необходимо предусмотреть возможности для ее управления по дальнейшим временным периодам $-t \in\left[T_{i}, T_{I}\right]$, где $i=K+1 .$. . При этом стремятся к тому, чтобы обеспечить выход рейтинговых показателей $R_{i}$ ее на более высокие позиции, чем для предыдущих временных периодов. В этом участвует соответствующий управляющий центр. В нем происходит принятие решений по тому, каким образом эффективность в функционировании будет поддерживаться. Кроме того, происходит ориентирование на соответствующую метрику в рейтинговании. Приходится применять анализ по данным мониторинга.

\section{Особенности системы, связанной с рейтинговым управле-} нием систем перевозок. В системах, позволяющих вести рейтингование и управление необходимо учитывать совокупность тех признаков, относительно которых осуществляется классификация. Именно они будут оказывать свое влияние на характеристики интеллектуальной поддержки [3], когда принимаются управленческие решения $[4,5]$.

Укажем ключевые признаки в системе рейтингования.

1. Наличие управляющего центра. Он рассматривается в виде организатора рейтингования.

2. Совокупность объектов, связанных с перевозками, относительно которых ведутся процессы рейтингования. Они представляются в виде соответствующего нумерационного множества $j=1 . . J$. Для них формируются общие $R_{j}$ и частные $R_{i j}$ рейтинговые оценки. Например, могут рассматриваться отделы в различных организациях

3. Определение подходов, на основе которых осуществляется формирование рейтинга относительно анализируемых объек- 
тов. Эксперты могут, например, опираться на такие способы: а) выбор интегральных оценок по их максимальным значениям, б) рассмотрение весов по каждому из показателей, в) сравнение по отклонениям от средних или нормативных значений.

Признаки, позволяющие осуществлять процесс классификации в системах рейтингового управления, могут быть такими:

1. Вид процедур принятия управленческих решений. Эксперты могут опираться только на нормативные документы, на указания вышестоящего руководства, на интеллектуальный анализ.

2. Способы распределения ресурсного обеспечения организаций перевозок. Например, преимущественно оно может идти на поддержку основных фондов, зарплатные статьи, перспективное планирование и реализацию.

3. Способы обеспечения управляющих воздействий для поддержки показателей эффективности работы организаций перевозок [6]. При этом ресурсы между ними могут распределяться разным образом: управление ведется как по основным фондам, так и перспективному развитию, в управлении могут происходить изменения, меняться приоритеты [7].

4. Число систем, связанных с рейтингованием. Это определяет число характеристик, связанных с оценкой эффективности.

5. Характеристики, используемые в системах рейтингования. Они могут быть разными: оценки по рейтингу, оценки на базе мониторинга.

6. Число периодов, внутри которых осуществляются процессы построения рейтинга.

В качестве основного признака, который возникает после проведения процедур классификации, можно указать признак 3. Он демонстрирует/, на что будет направлено управление, для чего потребуются соответствующие ресурсы.

Из этого признака вытекает и необходимость решения задач, относящихся к признаку 2.

Схема, приведенная на рис. 1, иллюстрирует особенности решения задач управления в системах перевозок, исходя из соответствующих признаков. 
Управленческие решения могут приниматься или на базе административных подходов или с привлечением интеллектуальных методов.

\section{Разработка оптимизационной модели, на базе которой при-} нимаются интеллектуальные решения. Если в системе будет использоваться интеллектуальная поддержка при принятии решений, тогда необходимо разрабатывать соответствующую оптимизационную модель. Распределение ресурсов в ходе действий управляющего центра должно быть оптимизировано [8]. На схеме видно, как управляющий центр распределяет ресурс W между основными фондами и направлениями перспективного развития. Для этого применяют соответствующую оптимизационную модель. Пусть в систему, связанную с перевозками, входят I компонентов у. Должны быть минимизированы затраты, относящиеся к основным фондам (их $\mathrm{n}$ видов). Стоимость обозначим как $c_{i n}$. Тогда оптимизационная модель будет такая:

$$
\sum_{i=1}^{I} \sum_{n=1}^{N} c_{\text {in }} y_{\text {in }} \rightarrow \min
$$

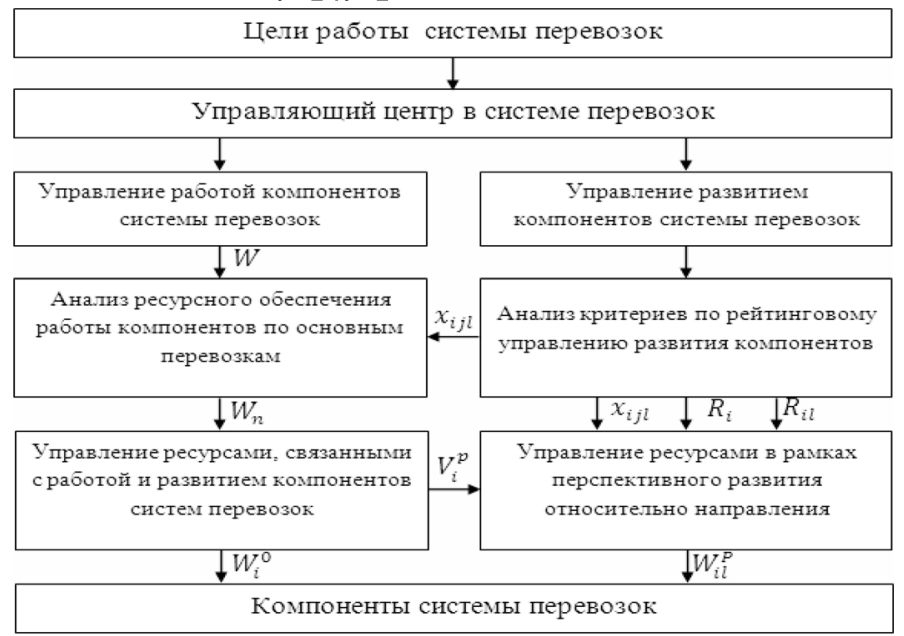

Рис. 1. Иллюстрация структурной схемы, связанной с рейтинговым управлением работы и перспективного развития систем перевозок 
Если принимать во внимание ограничения относительно соответствующего основного фонда (n), тогда их можно записать так:

$$
\sum_{i=1}^{I} w_{\text {in }} x_{i n} \geq V_{n}, n=\overline{1, N}
$$

здесь $w_{\text {in }}$ - иллюстрирует долю передачи $i$-й компонентой $n$-го ресурса в рамках $i$-х направлений работы.

Также есть ограничения сверху по ресурсам в ходе деятельности организации, связанной с перевозками

$$
\sum_{n=\overline{1}}^{N} w_{i n} x_{i n} \leq \widehat{W}_{n}, i=\overline{1, I} .
$$

В результате можно сформировать оптимизационную модель, базирующуюся на блочном линейном программировании

$$
\begin{gathered}
\sum_{i=1}^{I} \sum_{n=1}^{N} c_{i n} x_{i n} \rightarrow \min , \\
\sum_{i=\overline{1}}^{I} w_{i n} x_{i n} \geq W_{n}, n=\overline{1, N} \\
\sum_{n=\overline{1}}^{N} w_{i n} x_{i n} \leq \widehat{W}_{n}, i=\overline{1, I}
\end{gathered}
$$

Основываясь на решении этой задачи может быть определено перераспределение ресурсов в управляющем центре

$$
\begin{gathered}
W_{i}^{0}=\sum_{n=1}^{N} c_{i n} x_{i n}^{*}, i=\overline{1, I .} \\
W_{i}^{p}=\left(W_{i}-\sum_{n=1}^{N} w_{i n} x_{i n}^{*}\right)+W_{i}^{g},
\end{gathered}
$$

здесь управляющий центр может дать $V_{i}^{g}$ дополнение к ресурсу, если организация, связанная с перевозками, будет развиваться.

Особенности интеллектуальной поддержки в ходе процедур управления рейтингами. Можно использовать игровые методы. Предлагается формирование игры, которая будет эквивалентна оп- 
тимизационной задаче (4). При этом будет происходить переход от совокупности прямой и двойственной задач в линейном программировании к ситуациями, когда будет происходить игра между двумя лицами при нулевой сумме.

Решение соответствующих задач будет основываться на рассмотрении игры при соответствующей платежной функции.

\section{Выводы}

В рейтинговом управлении за счет обозначения соответствующих признаков в ходе классификации необходимо учитывать особенности распределения ресурсов в системах, связанных с перевозками. Управляющий центр должен рассматривать составляющие ресурсов по основным фондам и направлениям перспективного развития. Предложена оптимизационная модель, на базе которой может осуществляться при учете критериев оптимизации, интеллектуальная поддержка в ходе принятия решений.

Информация о конфликте интересов. Авторы заявляют об отсутствии конфликта интересов.

Информация о спонсорстве. Исследование не имело спонсорской поддержки.

\section{Список литературы}

1. Преображенский Ю.П. О повышении эффективности работы промышленных предприятий // Исследование инновационного потенциала общества и формирование направлений его стратегического развития. Сборник научных статей 8-й Всероссийской научно-практической конференции с международным участием. 2018. С. 45-48.

2. Преображенский Ю.П. Проблемы управления в производственных организациях // Актуальные проблемы развития хозяйствующих субъектов, территорий и систем регионального и муниципального управления Материалы XIII международной научно-практической конференции. Под редакцией Ю.В. Вертаковой. 2018. С. 208-211. 
3. Пеньков П.В. Экспертные методы улучшения систем управления // Вестник Воронежского института высоких технологий. 2012. № 9. С. 108-110.

4. Берман Н.Д., Белов А.М. Общественный транспорт и инновации // International Journal of Advanced Studies. 2019. T. 9. № 2. C. 7-13.

5. Шакиров А.А., Зарипова Р.С. Особенности моделирования логистических систем // International Journal of Advanced Studies. 2019. T. 9. № 4. C. 27-31.

6. Сапожникова С.М. Корпоративное управление в железнодорожном транспорте // International Journal of Advanced Studies. 2019. T. 9. № 4. С. 19-42.

7. Лысанов Д.М., Бикмухаметова Л.Т. Анализ показателей качества и конкурентоспособности оборудования // International Journal of Advanced Studies. 2018. T. 8. № 4-2. С. 50-55.

8. Преображенский Ю.П. Построение складской структуры предприятия // Молодежь и системная модернизация страны Сборник научных статей 3-й Международной научной конференции студентов и молодых ученых. В 4-х томах. Ответственный редактор А.А. Горохов. 2018. С. 286-290.

\section{References}

1. Preobrazhenskij Yu.P. Issledovanie innovacionnogo potenciala obshchestva i formirovanie napravlenij ego strategicheskogo razvitiya. Sbornik nauchnyh statej 8-j Vserossijskoj nauchno-prakticheskoj konferencii s mezhdunarodnym uchastiem [Research on the innovative potential of society and the formation of directions for its strategic development. Collection of scientific articles of the 8th All-Russian Scientific and Practical Conference with international participation]. 2018, pp. 45-48.

2. Preobrazhenskij Yu.P. Aktual'nye problemy razvitiya hozyajstvuyushchih sub"ektov, territorij i sistem regional'nogo i municipal'nogo upravleniya Materialy HIII mezhdunarodnoj nauchno-prakticheskoj konferencii [Actual problems of the development of business entities, territories and systems of regional and municipal management Mate- 
rials of the XIII international scientific and practical conference]. Ed. Yu.V. Vertakova. 2018. S. 208-211.

3. Pen'kov P.V. Vestnik Voronezhskogo instituta vysokih tekhnologij. 2012. № 9, pp. 108-110.

4. Berman N.D., Belov A.M. International Journal of Advanced Studies. 2019. V. 9. № 2, pp. 7-13.

5. Shakirov A.A., Zaripova R.S. International Journal of Advanced Studies. 2019. V. 9. № 4, pp. 27-31.

6. Sapozhnikova S.M. International Journal of Advanced Studies. 2019. V. 9. № 4, pp. 19-42.

7. Lysanov D.M., Bikmuhametova L.T. International Journal of Advanced Studies. 2018. V. 8. № 4-2, pp. 50-55.

8. Preobrazhenskij Yu.P. Molodezh' i sistemnaya modernizaciya strany Sbornik nauchnyh statej 3-j Mezhdunarodnoj nauchnoj konferencii studentov i molodyh uchenyh [Youth and system modernization of the country Collection of scientific articles of the 3rd International Scientific Conference of Students and Young Scientists]. Ed. A.A. Gorohov. 2018. S. 286-290.

\section{ДАННЫЕ ОБ АВТОРАХ}

Львович Яков Евсеевич, профессор, доктор технических наук, профессор Федеральное государственное образовательное учреждение выстего образования Воронежский государственный технический университет

ул. 20 лет Октября, 84, г. Воронеж, 394006, Российская Федерация

Komkovvivt@yandex.ru

Преображенский Андрей Петрович, профессор, доктор технических наук, доцент Автономная некоммерческая образовательная организачия высшего образования Воронежский институт высоких технологий 
ул. Ленина, 73а, г. Воронеж, 394043, Российская Федераџия Komkovvivt@yandex.ru

Чопоров Олег Николаевич, профессор, доктор технических наук, профессор

Федеральное государственное образовательное учреждение высшего образования Воронежский государственный технический университет

ул. 20 лет Октября, 84, г. Воронеж, 394006, Российская Федераичи

Komkovvivt@yandex.ru

\section{DATA ABOUT THE AUTHORS}

Lvovich Yakov Yevseevich, Professor, doctor of technical Sciences, Professor

Voronezh State Technical University

20 years of October Str., 84, Voronezh, 394006, Russian Federation Komkovvivt@yandex.ru

ORCID: 0000-0002-7051-3763

Preobrazhenskiy Andrey Petrovich, professor, doctor of technical sciencies, associate professor Voronezh Institute of High Technologies

73a, Lenin Str., Voronezh, 394043, Russian Federation

Komkovvivt@yandex.ru

ORCID: 0000-0002-6911-8053

Choporov Oleg Nikolaevich, Professor, doctor of technical Sciences, Professor

Voronezh State Technical University

20 years of October Str., 84, Voronezh, 394006, Russian Federation

Komkovvivt@yandex.ru

ORCID: 0000-0002-3176-499X 